\title{
Reality Shock Among Field Training Students at the Special Education Department at Qassim University and Its Relation With Their Adjustment Strategies and Future Attitude Toward the Profession
}

\author{
Lawaheth M. T. Hussain, Safaa M. A. Yadak \\ Qassim University, Al-Rass, KSA
}

\begin{abstract}
The study examined reality shock among field training students, its relation with adjustment strategies and attitude in future toward the profession. Eighty students from special education department participated. Three tests were constructed: future attitude toward the profession; reality shock and adjustment strategies. Tests validity and reliability were established. Field training students had reality shock, reasons were attributed to students of special needs at schools scored first. There was a relationship between reality shock and dimensions attributed to students paths. Statistical differences between reality shock and students attitude in future for the profession attributed to paths were not found. Statistical significant differences in students attitude in future for the profession between pre and posttests in favor of the pretest were found. Psychological and physical adjustment strategies were used to ease reality shock among students more, but social adjustment strategies scores were low. Adjustment strategies did not differ according to students path in all dimensions and overall test.
\end{abstract}

Keywords: reality shock, adjustment strategies, future attitude toward the profession, field training

\section{Introduction}

Working with special education children is considered a humanitarian action and it includes providing educational and remedial services to the individuals who need it. This field grew rapidly and it has benefited from the domains of education, psychology, sociology and medicine. So it has become one of the recognized fields for its importance and effectiveness in providing services for many individuals who need it. Working in this field needs preparation and training, the major of special needs at the university ends in its last year with field training for the students in schools of merging special needs students in regular schools (Hallahan \& Kauffman, 1991).

Weinstein (1988) believes that the student teacher transition from academic settings at the university into actual teaching in schools exposes him to reality shock or the shock of transition from theoretical preparation into field preparation. This shock may lead into a breakdown of theoretical ideals because of the hard special needs school facts (Merrett \& Wheldall, 1993). This would result in negative attitude development

Lawaheth M. T. Hussain, Assisstant professor, Faculty of Arts and Sciences, Qassim University.

Safaa M. A. Yadak, Assisstant professor, Faculty of Arts and Sciences, Qassim University. 
toward the teaching profession and a feeling that it is not suitable (Hayon \& Beretz, 1988). Reality shock occurs when the individual feels that the requirements of the situation facing him exceeds his ability to confront it, or deal with it, which creates a state of imbalance between the requirements of the shocking situation, and his ability to respond to it, hence, feels the shock dominates him, but if he can adjust to the requirements the shock becomes acceptable and useful, this is the positive side of the psychological shock, the aim is to motivate individuals to use new adjustment strategies to confront problems and shocking situations (Lazarus, 1966).

Through the above the reality shock refers to existence of stressful external factors on the individual which creates tension or distortion in the personal integration, when the intensity of these shocks increase the individual may lose the ability to balance and change his behavior pattern into new patterns. The psychological shock individuals suffer when faced with something that exceeds his ability or when he encompasses a severe conflict or extreme shyness and if the shock caused real harm to the individual he becomes frustrated (Abdel-Azeem, 2006).

Lazarus and Folkman (1984) mentioned that shocking situations occur when individuals realize that internal and external resources are not sufficient to adjust and deal with the surroundings and feel also threatened. Accordingly, pressure occur after the individual primarily assess cognitively the situation as a pressurizing and threatening one and second assess if his confrontation resources will reduce the situation pressure or not and will it reduce negative emotions caused by the situation or not, therefore confrontation becomes a process not a result.

Reality shock studies focused recently on the individual's positive aspects, variables that maintain physical, psychological and social in good health while confronting the situation. Few studies dealt with adjustment strategies as the most positive important variables such as the study of Ganellen and Blarney (1984). Da'na (1994) indicated that adjustment strategies represent the individuals continues pursue to adjust between his demands, circumstances and the demands and circumstances of the surrounding environment. The individual often finds himself in situations that do not satisfy his demands and needs, rather these might be a source of hindrance toward satisfying sociopsychological needs. Hence adjustment strategies might be considered as personal readiness and features as well as continuous developing strategies in pressurizing situations by demands of the environment.

Lazarus and Folkman (1984) said that adjustment strategies are the efforts made by the individual to control, reduce or endure internal and external demands that are caused by shocking situations. Abdel-Azeem (2006) defines strategies as the actions that enable individuals to comply with environment conditions, and the effective or procedural behavior. It is an action in which the individual interacts with his environment for the purpose of achieving something.

Hardy (as cited in Jodah, 2004, p. 674) defines adjustment strategies as "individual cognitive, emotional, psychomotor and environmental efforts in which the individual confronts shocking situations to prevent it, avoid its negative moral and material effects or decrease it to maintain emotional balance and psychosocial adjustment".

Lazarus and Folkman (as cited in Hasan, 2006, pp. 91-92) wrote about two essential functions for the adjustment strategies: the first is concerned with organization of emotions resulting from the shocking situation; the second deals with the problem resulting from the shocking situation. According to the authors, these two functions are used in most shocking situations, they are not contradicted and individuals use a 
combination of them in confronting many shocking situations. Nevertheless, the existence of some variables indicate to using one function over the other; organization of emotions is used if the individual believes that the shocking situation is ongoing, may not be changed and must be endured. While the function of dealing with the problem is used in the situations in which individuals believe something useful may happen concerning the problem.

Bootzin (1991) believes there are two functions of adjustment strategies; adjusting the relationship between the individual and his irritating environment and controlling pressurizing emotions. He believes that individuals able to use adjustment strategies are able to solve difficulties confronting them by changing the environment that causes pain or threatens them, they organize their emotions by maintaining a positive image of their selves.

Higgins and Endler (1995) referred to three adjustment strategies in confronting shocking situations; the first is emotional oriented referring to emotional reactions, reflects behavior in problem processing and includes emotions of distress, tension, anxiety, discomfort, anger, grief and despair. The second is avoidance oriented referring individuals attempts to avoid direct confrontation of shocking situations and content with withdrawal from the situation. The third is task oriented referring to individuals active behavioral attempts of direct processing of the problem in a realistic and rational manner, it includes recognizing the real causes of the problem, benefiting from previous situations expertise, suggesting alternatives to process the problem and chose the best and setting an immediate plan to confront the problem.

The global attitude in education development confirms that education is a type of service provided to the student audience; it requires a commitment to the professional charter, toward the profession, students and community in addition to having knowledge and technical skills (Alian \& Shakhshir, 2007).

Teacher's success factor lies in positive attitude toward the profession, which is according to Cook (1986, as cited in Al-Omary, 1989) is the foundation of which teachers start designing educational activities. Teacher's attitude toward the major at the university is correlated with the academic preparation and at the same time is a reflection of the image about teaching. Educational programs are criticized for focusing on the descriptive cognitive dimension and not being interested at acquiring field expertise and appropriate positive directions. Academic preparation on its own is not enough to form positive attitude toward the profession and towards special needs students, there should be professional setting to help the teachers to confront work pressures especially with special needs students.

Thus, adjustment strategies correlate closely with the attitude toward the profession. Attitude is defined as the mental and neurological readiness state, it is organized by experience and practices guidance or dynamic effect on individuals response toward all issues or toward the situations correlated with the response, attitude consists of three components according to Al-Omary (1989):

(1) The cognitive component: Includes ideas, experiences, information and situations that the students encounter in their university life which influence his point of view toward the teaching profession, which in turn lead to formation of the emotional component; (2) The emotional component: It is based on the cognitive processes and refers to the emotional aspects that helps and determines the type of the student attachment with the teaching profession, that is, it guarantees a presentation of the preference. The relation between the cognitive and emotional components is causal; they may not be separate in any activity. There is a cognitive component for each emotional aspect and vice versa; and (3) The behavioral component: It is the student attitude toward teaching, this attitude should be consistent with the student's emotions and knowledge about the 
profession; that is all the behavioral readiness associated with the attitude and represented by responses resulting from the development of the cognitive and emotional component.

The poor consistency that may encounter the student at the beginning of his profession may be dangerous if not treated; individually it appears clearly in the feelings of fatigue, less sleeping, burnout in addition to acute stress, ulcers, muscle spasm and increased number of the heartbeat. Professionally it is reflected in absenteeism from work or leaving it. Students may respond to psychological stress by the previous learnt behavior, but if this behavior is not sufficient the necessity of adjustment to encounter various professional, psychological, and social stresses, where the student collects multiple elements from his experiences to determine the style of new response to the new situation (Al-Quds Open University, 1997).

The current study according to the authors attempted to explore the reality shock among the field training students at the special education department at Qassim University and its relation with their adjustment strategies and future attitude toward the profession.

\section{Literature Review}

Arab and local literature on "reality shock among the field training students majoring in special education and its relation with their adjustment strategies and future attitude toward the profession" do not exist as far as the authors know. But few studies where interested in adjustment strategies and students attitude toward teaching, these are divided into three sections in this study. Following a review of these studies.

\section{Reality Shock Studies}

Muhaisin (1997) studied the potential of finding reality shock among field training postgraduates from all majors $(N=150)$ when practicing teaching, in addition to their ability to deal with students unusual behavior patterns. No obvious implications of reality shock where found among the postgraduates, but they were having difficulty in dealing with students unusual behavior patterns which was attributed to the poor setting of regular courses and field training courses at the university.

Sehba (2013) studied transition shock among kindergarten teachers of the real teaching process. Participants were from KG1 teachers $(N=24)$ in public and private institutions, they were interviewed and responses revealed that transition is a source of anxiety, analysis of the responses revealed that the cause of the shock is attributed to the difference between their previous perspectives about teaching and the effect of being real teachers, and their attempts to practice their learning experiences in real teaching life, they also expressed their opinions about working in environments that are poor in teaching and learning resources. Their real challenge was to move into the real world of teaching and accounting for the fact of working in a different context in kindergarten stage compared with other teachers.

In a recent study, Kim and Cho (2014) studied reality shock among beginner teachers attitude toward the profession and teaching efficacy. Beginner teachers from the state university in USA $(N=533)$ participated in the study, their attitude toward teaching was measured before and after starting teaching. It was proved that reality shock has a negative effect on teacher's efficacy and their intrinsic motivation toward the profession.

\section{Adjustment Strategies Studies}

Kardum and Krapić (2003) examined the relationship between the characteristics, stressful life events and confronting methods in early adolescents. Two hundred sixty five adolescents were subjected to target pressure 
and stressful life events tests. A positive effect of extroversion style in confronting problems and confronting emotions is found. Neurological scientists focused on the method of confrontation avoidance.

Jodah (2004) studied the correlation between the psychological stress confrontation and psychological health among Al-Aqsa University postgraduates with gender, major and place of residence, and to determine the effect of psychological stress confrontation among (100) male and (100) female postgraduates. It was found that participants use different methods in confronting stressful life events, some differences were functional in some of the stressful life events dimensions attributed to the major variable.

Raja (2007) aimed to identify the strategies used by students in dealing with psychological shocks, and determine if the differences are attributed to their majors in the faculty of education. Participants (115) male and (155) female completed the test of Coping Responses Inventory Adult Form which was developed by Rudolf Moss (1993, as cited in Raja, 2007). It was found that students tend toward using approach strategies more than using avoidant strategies, females tend to use the strategies of catharsis, in terms of students majors results showed that approach strategies were used more among students psychological counseling and psychology majors.

Arabyat and Kharabsheh (2007) studied the psychological stressors, how outstanding students deal with it and their strategies. The participants were $(N=256)$ students from the educational institutions in Jordan. It was found that the most used strategy was tranquillizers and the less used was benefiting from previous experiences.

\section{Future Attitude Toward the Profession Studies}

Obani and Doherty (1984) examined some of the factors that influence attitude toward teaching profession of disabled children by examining students teachers attitudes. Female students teachers had positive attitudes toward teaching compared to males. It was also found that males aged 25 years had more positive attitudes compared with older participants. Certain preferences are found for certain disability categories, male students teachers who worked with mental retarded children were (101), while females working with blind children scored (10\%).

Dignan (2003) studied 400 participants' attitudes toward future profession and found that the most of them who joined the profession of teaching special needs children because they loved working with disabled children, loved teaching or they did not like traditional teaching scoring $(16.5 \%)$, teaching represented a stimulation of energies and abilities of (12.1\%), for (9.2\%) it represented an available job, for (9.2\%) they had contacts with others in the profession or had a disabled child in their families, $(23.1 \%)$ decided to teach while they were studying, (13.9\%) had contacts with blind people and (9.8\%) new about the job through friends of family members.

Haussatter (2007) studied the reasons for choosing special needs education major and the challenges facing the process of merging, what is expected to be learnt while studying. It was found that the main reason was to help low achievers in improving their grades, and to provide treatment for the disabled students by learning counseling and guidance in studying.

Petrovary (2008) studied the characteristics and profession expectations correlated with choosing to teach blind students. The participants $(N=132)$ were trained before and after graduation, Holland self-directed test was implemented and it was found that the participants were willing to work with blind children.

An overview on the previous literature, and as far as the authors know, there were no Arabic studies interested in shocking training situations, while studies about adjustment strategies and attitude toward the 
profession are found. The difference between previous studies and the current one is examining reality shock and its correlation with adjustment strategies and attitude toward the profession among field training students at the special needs education department, to develop academic and practical practices. The authors hope that this study will be the core for further studies in future, in light of the lack of Arabic and local studies.

\section{Study Problem}

Field training students are subject to the reality shock when the start field training and working with special needs students. This shock is correlated with adjustment strategies and their future attitude toward the teaching profession. Therefore, the current study attempted to study reality shock among field training students at the faculty of arts and sciences majoring in learning difficulties and speech disorders at Qassim University and the relation with their adjustment strategies and future attitude toward the profession in the academic year 2015/2016. Accordingly, the current study tried to answer the following questions:

(1) What is the field training student's exposure degree to reality shock and its dimensions?

(2) Are there statistical significant differences for the exposure degree to reality shock and its dimensions attributed to the path (learning difficulties and speech disorders)?

(3) Is the relationship between reality shock and students attitude toward the profession attributed to path (learning difficulties and speech disorders) different?

(4) Are there statistical significant differences in pre and posttests of field training students attitudes attributed to toward the profession?

(5) What are the adjustment strategies used by field training students in both paths (learning difficulties and speech disorders) toward reality shock?

(6) Are there statistical significant differences in students adjustment strategies attributed to the path (learning difficulties and speech disorders)?

\section{Importance of the Study}

Field training is very important to prepare students teachers at Education Department/ Faculty of Arts and Sciences/ Al-Rass to the practice, and important to develop. This issue is studied as an actual problem that requires an academic practical intervention, and an attempt to formulate scientific and practical preventive measures that improves student's abilities to adjust and improve student's field training performance.

\section{Goals of the Study}

The study aimed at studying the factors and reasons that field training students face when exposed to reality shock after they transfer to practice teaching in the schools of special needs, and to recognize students teachers adjustment strategies and the effect of it on their attitude in future toward the profession.

\section{Limitations of the Study}

The authors believe that generalizing the results of this study may be inhibited through the following:

Validity and reliability of the tests: The sample chosen from Qassim University for the academic year 2015/2016 total number of (80) majoring in learning difficulties and speech disorders. Hence the results are valid to generalize only on the population of this study and similar populations.

\section{Procedural Definitions}

Reality shock. Is a negative emotional psychological state such as anger, anxiety, frustration, lack of endurance, irritation or discouragement that the students of field training encounter after practicing teaching in 
special needs schools, to discover the difference between actual teaching and what is learnt at the university, measured by the scores achieved on reality shock test.

Adjustment strategies. The strategies used by the student teachers in confronting shocking situations and crises encountered in field training course at special needs schools, measured by the scores achieved on adjustment strategies test.

Future attitude toward the profession. It is a relatively constant organization, the formulation of changing the response toward the profession if students information is changed about it or because of shocking situations measured by the scores achieved on pre and posttest.

Field training students in the department of special needs. In light of the authors understanding field training students "training to be teachers supervised by academic advisor and a collaborated teacher to help these students in teaching special needs students the skills that will help them to depend on themselves and survive".

\section{Methods}

\section{Participants}

The study sample consisted of (80) female students, they were enrolled in the special education major at Qassim University for the academic year 2015/2016.

Table 1

Repetition and Percentage Based on the Groups

\begin{tabular}{lll}
\hline Categories & Repetition & Percentage (\%) \\
\hline Special education speech disorders & 40 & 50 \\
Special education learning difficulties & 40 & 50 \\
\hline
\end{tabular}

\section{Measures}

Three tests are constructed: Reality shock, adjustment strategies and future attitude toward the profession.

Constructing the test of future attitude toward the profession. Test initial version consisted of (32) items, as illustrated in appendix 1, including all important aspects needed for teachers, subjects completed test items on a 5-point Likert scale ranging from (1) "Strongly agree" to (5) "Strongly disagree". Student's views were surveyed by asking them open questions about their attitude toward the teaching profession, in addition to considering some of the other studies tests items such as Qaraqzah (2004).

Items validity for the local environment was verified by a number of competent professors majoring in psychology and learning and curriculum, five competent teachers, from the special needs schools at Qassim public schools who were able to review and judge the test items based on their actual professional suffering provided comments in terms of dimension representation, suitability to the age group, and the structure of the items.

Validity and reliability of field training students future attitude toward the profession test. Surface validity. Competent professors reviewed the initial version of the test. The professors provided some remarks on the test items in terms of dimension representation, suitability to the age group, and structure, based on their comments two items are excluded and others are revised ( $80 \%$ of the reviewers agreed on their unsuitability) the total final number of items was (30) items. Accordingly, the total score for the (30) item test ranged between (30-150) degrees. 
Construct validity. The test was implemented on a pilot sample of (20) students to verify the validity of the instructions clarity, items clarity, scoring instructions and writing notes and comments. Items and overall of the test correlation coefficients are calculated, scores ranged between (0.40-0.76), as Table 2 illustrates.

Table 2

Correlation Coefficient of Field Training Students Future Attitude Toward the Profession Based on Test Dimensions and Overall Test

\begin{tabular}{llllll}
\hline No. & Test correlation coefficient & No. & Test correlation coefficient & No. & Test correlation coefficient \\
\hline 1 & $0.52^{* *}$ & 11 & $0.46^{* *}$ & 21 & $0.53^{* *}$ \\
2 & $0.67^{* *}$ & 12 & $0.76^{* *}$ & 22 & $0.56^{* *}$ \\
3 & $0.74^{* *}$ & 13 & $0.46^{* *}$ & 23 & $0.49^{* *}$ \\
4 & $0.66^{* *}$ & 14 & $0.54^{* *}$ & 24 & $0.43^{* *}$ \\
5 & $0.50^{* *}$ & 15 & $0.74^{* *}$ & 25 & $0.61^{* *}$ \\
6 & $0.54^{* *}$ & 16 & $0.40^{* *}$ & 26 & $0.50^{* *}$ \\
7 & $0.58^{* *}$ & 17 & $0.71^{* *}$ & 27 & $0.60^{* *}$ \\
8 & $0.68^{* *}$ & 18 & $0.50^{* *}$ & 28 & $0.72^{* *}$ \\
9 & $0.54^{* *}$ & 19 & $0.72^{* *}$ & 29 & $0.58^{* *}$ \\
10 & $0.61^{* *}$ & 20 & $0.44^{* *}$ & 30 & $0.56^{* *}$ \\
\hline
\end{tabular}

Note. ${ }^{*} \alpha$ functional at $(\alpha=0.05),{ }^{* *} \alpha$ functional at $(\alpha=0.01)$.

All the correlation coefficient were acceptable and statistically significant, therefore, none of the items were excluded.

Reliability of field training students future attitude toward the profession test. A pilot sample of (20) students were exposed to the test and retested after an interval of two weeks. Coefficients are calculated, Pearson correlations scored (0.93) and internal consistency is calculated by Cronbach Alpha, it scored (0.91).

Constructing the test of reality shock. Surveying the views of a number of trainees working in the field and academic supervisors a number of items (53) were derived. Items covered five dimensions; the training student dimension consisted of (13) items, reasons related to academic and professional preparation dimension consisted of (10) items, reasons correlated with the academic supervisor dimension consisted of (10), concerned with the students at the special needs school consisted of (10) items and the dimension of cooperative teacher and school administration consisted of (10) items.

Surface validity. Competent professors majoring in psychology and guidance and counseling reviewed the initial version of the test. The professors provided some comments in terms of dimension representation and the structure of the items. Based on their comments ( $80 \%$ of the reviewers agreed on their unsuitability) some items were reframed the items final version was (53). Subjects completed test items on a 5-point Likert scale ranging from (1) "Strongly agree" to (5) "Strongly disagree". Accordingly, the total score of the overall test ranged between (53-265) degrees. Instructions of completing the test were provided. The test was implemented on random pilot sample of (20) students to collect their comments and views about the test, comments were considered.

Construct validity. Correlation coefficients of the test items were calculated from the results of the pilot sample, scoring ranged between $(0.32-0.66)$ on the overall test and (0.31-0.66) with the dimensions are illustrated in Table 3. 
Table 3

\begin{tabular}{|c|c|c|c|c|c|c|c|c|}
\hline No. & $\begin{array}{l}\text { Correlation } \\
\text { coefficient with the } \\
\text { dimension }\end{array}$ & $\begin{array}{l}\text { Correlation } \\
\text { coefficient of } \\
\text { overall test }\end{array}$ & No. & $\begin{array}{l}\text { Correlation } \\
\text { coefficient with } \\
\text { the dimension }\end{array}$ & $\begin{array}{l}\text { Correlation } \\
\text { coefficient of } \\
\text { overall test }\end{array}$ & No. & $\begin{array}{l}\text { Correlation } \\
\text { coefficient with } \\
\text { the dimension }\end{array}$ & $\begin{array}{l}\text { Correlation } \\
\text { coefficient of } \\
\text { overall test }\end{array}$ \\
\hline 1 & $0.34^{*}$ & $0.35^{*}$ & 19 & $0.33^{*}$ & $0.46^{* *}$ & 37 & $0.53^{* *}$ & $0.33^{*}$ \\
\hline 2 & $0.55^{* *}$ & $0.46^{* *}$ & 20 & $0.52^{* *}$ & $0.56^{* *}$ & 38 & $0.36^{*}$ & $0.33^{*}$ \\
\hline 3 & $0.49^{* *}$ & $0.36^{* *}$ & 21 & $0.47^{* *}$ & $0.35^{*}$ & 39 & $0.57^{* *}$ & $0.44^{* *}$ \\
\hline 4 & $0.33^{*}$ & $0.55^{* *}$ & 22 & $0.45^{* *}$ & $0.44^{* *}$ & 40 & $0.40^{* *}$ & $0.32^{*}$ \\
\hline 5 & $0.31^{*}$ & $0.33^{*}$ & 23 & $0.53^{* *}$ & $0.49^{* *}$ & 41 & $0.55^{* *}$ & $0.66^{* *}$ \\
\hline 6 & $0.40^{* *}$ & $0.42^{* *}$ & 24 & $0.46^{* *}$ & $0.51^{* *}$ & 42 & $0.50^{* *}$ & $0.32^{*}$ \\
\hline 7 & $0.37^{* *}$ & $0.49^{* *}$ & 25 & $0.45^{* *}$ & $0.55^{* *}$ & 43 & $0.44^{* *}$ & $0.52^{* *}$ \\
\hline 8 & $0.45^{* *}$ & $0.56^{* *}$ & 26 & $0.43^{* *}$ & $0.44^{* *}$ & 44 & $0.58^{* *}$ & $0.45^{* *}$ \\
\hline 9 & $0.62^{* *}$ & $0.41^{* *}$ & 27 & $0.38^{* *}$ & $0.32^{*}$ & 45 & $0.52^{* *}$ & $0.45^{* *}$ \\
\hline 10 & $0.50^{* *}$ & $0.43^{* *}$ & 28 & $0.66^{* *}$ & $0.57^{* *}$ & 46 & $0.45^{* *}$ & $0.43^{* *}$ \\
\hline 11 & $0.43^{* *}$ & $0.50^{* *}$ & 29 & $0.35^{*}$ & $0.46^{* *}$ & 47 & $0.50^{* *}$ & $0.40^{* *}$ \\
\hline 12 & $0.41^{* *}$ & $0.32^{*}$ & 30 & $0.55^{* *}$ & $0.55^{* *}$ & 48 & $0.51^{* *}$ & $0.64^{* *}$ \\
\hline 13 & $0.52^{* *}$ & $0.41^{* *}$ & 31 & $0.43^{* *}$ & $0.54^{* *}$ & 49 & $0.51^{* *}$ & $0.35^{*}$ \\
\hline 14 & $0.57^{* *}$ & $0.47^{* *}$ & 32 & $0.48^{* *}$ & $0.56^{* *}$ & 50 & $0.31^{*}$ & $0.44^{* *}$ \\
\hline 15 & $0.55^{* *}$ & $0.58^{* *}$ & 33 & $0.48^{* *}$ & $0.50^{* *}$ & 51 & $0.45^{* *}$ & $0.30^{*}$ \\
\hline 16 & $0.32^{*}$ & $0.36^{*}$ & 34 & $0.43^{* *}$ & $0.45^{* *}$ & 52 & $0.32^{*}$ & $0.32^{*}$ \\
\hline 17 & $0.34^{*}$ & $0.49^{* *}$ & 35 & $0.42^{* *}$ & $0.57^{* *}$ & 53 & $0.63^{* *}$ & $0.63^{* *}$ \\
\hline 18 & $0.31^{*}$ & $0.42^{* *}$ & 36 & $0.35^{*}$ & $0.40^{* *}$ & & & \\
\hline
\end{tabular}

Note. ${ }^{*} \alpha$ functional at $(\alpha=0.05),{ }^{* *} \alpha$ functional at $(\alpha=0.01)$.

All the correlation coefficient were acceptable and statistically significant, therefore, none of the items were excluded.

Table 4

Correlation Coefficient of Reality Shock Based on Test Dimensions and Overall Test

\begin{tabular}{|c|c|c|c|c|c|c|}
\hline & Training student & $\begin{array}{l}\text { Academic and } \\
\text { professional } \\
\text { preparation }\end{array}$ & $\begin{array}{l}\text { Academic } \\
\text { supervisor }\end{array}$ & $\begin{array}{l}\text { Students at the } \\
\text { special needs } \\
\text { school }\end{array}$ & $\begin{array}{l}\text { Cooperative } \\
\text { teacher and } \\
\text { school } \\
\text { administration }\end{array}$ & Overall test \\
\hline Training student & 1 & & & & & \\
\hline $\begin{array}{l}\text { Academic and } \\
\text { professional preparation }\end{array}$ & $0.436^{* *}$ & 1 & & & & \\
\hline Academic supervisor & $0.421^{* *}$ & $0.537^{* *}$ & 1 & & & \\
\hline $\begin{array}{l}\text { Students at the special } \\
\text { needs school }\end{array}$ & $0.478^{* *}$ & $0.300^{*}$ & 00.028 & 1 & & \\
\hline $\begin{array}{l}\text { Cooperative teacher and } \\
\text { school administration }\end{array}$ & $0.391^{* *}$ & $0.386^{* *}$ & $0.364^{* *}$ & $0.501^{* *}$ & 1 & \\
\hline Overall test & $0.657^{* *}$ & $0.722^{* *}$ & $0.656^{* *}$ & $0.594^{* *}$ & $0.702^{* *}$ & 1 \\
\hline
\end{tabular}

Note. ${ }^{*} \alpha$ functional at $(\alpha=0.05),{ }^{* *} \alpha$ functional at $(\alpha=0.01)$.

Reliability of reality shock test. A pilot sample of (20) students were exposed to the test and retested after an interval of two weeks. Pearson correlations coefficients, internal consistency and test retest reliability were calculated as illustrated in Table 5 .

Constructing the test of adjustment strategies. Surveying the views of a pilot sample, literature review and relevant tests, (30) items were derived covering three dimensions of the adjustment strategies test; 
psychological adjustment strategies consisted of (10) items, social adjustment strategies consisted of (10) items and physical adjustment strategies consisted of (10) items.

Table 5

Alpha Internal Consistency and Test Retest Based on the Dimensions and Overall Test

\begin{tabular}{lll}
\hline Dimension & Test Retest & Internal Consistency \\
\hline Training student & 0.89 & 0.83 \\
Academic and professional preparation & 0.91 & 0.79 \\
Academic supervisor & 0.90 & 0.82 \\
Students at the special needs school & 0.88 & 0.79 \\
Cooperative teacher and school administration & 0.87 & 0.76 \\
Overall test & 0.90 & 0.92 \\
\hline
\end{tabular}

Validity and reliability of adjustment strategies test. Again competent professors majoring in psychology and learning and curriculum reviewed the initial version of the test, they provided remarks on the test items in terms of dimension representation and suitability for the local environment. Based on the comments some items were reconstructed, the total final number of items was (30) items. Items scoring ranged from (1) "Strongly agree" to (5) "Strongly disagree" on a 5-point Likert scale. Accordingly, the total score of the overall test ranged between (30-150) degrees. Instructions of completing the test were provided as in previous tests. The test was implemented on random pilot sample of (20) students to collect their comments and views about, all comments were considered.

Construct validity. Correlation coefficients of the test items were calculated from the results of the pilot sample, scoring ranged between $(0.39-0.60)$ on the overall test and $(0.38-0.69)$ with the dimensions are illustrated in Table 6.

Table 6

Correlation Coefficient of Adjustment Strategies Based on Test Items and Overall Test

\begin{tabular}{|c|c|c|c|c|c|c|c|c|}
\hline No. & $\begin{array}{l}\text { Correlation } \\
\text { Coefficient with the } \\
\text { dimension }\end{array}$ & $\begin{array}{l}\text { Correlation } \\
\text { Coefficient } \\
\text { overall test }\end{array}$ & No. & $\begin{array}{l}\text { Correlation } \\
\text { Coefficient with the } \\
\text { dimension }\end{array}$ & $\begin{array}{l}\text { Correlation } \\
\text { Coefficient } \\
\text { overall test }\end{array}$ & No. & $\begin{array}{l}\text { Correlation } \\
\text { Coefficient } \\
\text { with the } \\
\text { dimension }\end{array}$ & $\begin{array}{l}\text { Correlation } \\
\text { Coefficient } \\
\text { overall test }\end{array}$ \\
\hline 1 & $0.48^{* *}$ & $0.40^{* *}$ & 11 & $0.38^{* *}$ & $0.42^{* *}$ & 21 & $0.60^{* *}$ & $0.39^{* *}$ \\
\hline 2 & $0.56^{* *}$ & $0.49^{* *}$ & 12 & $0.61^{* *}$ & $0.50^{* *}$ & 22 & $0.46^{* *}$ & $0.40^{* *}$ \\
\hline 3 & $0.51^{* *}$ & $0.46^{* *}$ & 13 & $0.47^{* *}$ & $0.43^{* *}$ & 23 & $0.61^{* *}$ & $0.53^{* *}$ \\
\hline 4 & $0.55^{* *}$ & $0.40^{* *}$ & 14 & $0.51^{* *}$ & $0.46^{* *}$ & 24 & $0.61^{* *}$ & $0.52^{* *}$ \\
\hline 5 & $0.61^{* *}$ & $0.50^{* *}$ & 15 & $0.66^{* *}$ & $0.52^{* *}$ & 25 & $0.56^{* *}$ & $0.45^{* *}$ \\
\hline 6 & $0.51^{* *}$ & $0.45^{* *}$ & 16 & $0.65^{* *}$ & $0.60^{* *}$ & 26 & $0.45^{* *}$ & $0.47^{* *}$ \\
\hline 7 & $0.69^{* *}$ & $0.58^{* *}$ & 17 & $0.64^{* *}$ & $0.52^{* *}$ & 27 & $0.50^{* *}$ & $0.42^{* *}$ \\
\hline 8 & $0.64^{* *}$ & $0.52^{* *}$ & 18 & $0.53^{* *}$ & $0.50^{* *}$ & 28 & $0.55^{* *}$ & $0.55^{* *}$ \\
\hline 9 & $0.61^{* *}$ & $0.45^{* *}$ & 19 & $0.44^{* *}$ & $0.48^{* *}$ & 29 & $0.38^{* *}$ & $0.42^{* *}$ \\
\hline 10 & $0.57^{* *}$ & $0.44^{* *}$ & 20 & $0.44^{* *}$ & $0.47^{* *}$ & 30 & $0.62^{* *}$ & $0.45^{* *}$ \\
\hline
\end{tabular}

Note. ${ }^{*} \alpha$ functional at $(\alpha=0.05),{ }^{* * *} \alpha$ functional at $(\alpha=0.01)$.

All the correlation coefficient were acceptable and statistically significant, therefore, none of the items were excluded.

Reliability of adjustment strategies test. A pilot sample of (50) students were exposed to the test and retested after an interval of two weeks. Pearson correlations coefficients, internal consistency and test retest reliability were calculated as illustrated in Table 8 . 
Table 7

Correlation Coefficient of Adjustment Strategy Based on Test Dimensions and Overall Test

\begin{tabular}{lllll}
\hline & $\begin{array}{l}\text { Psychological } \\
\text { adjustment } \\
\text { strategies }\end{array}$ & $\begin{array}{l}\text { Social adjustment } \\
\text { strategies }\end{array}$ & $\begin{array}{l}\text { Physical } \\
\text { adjustment } \\
\text { strategies }\end{array}$ & Overall test \\
\hline $\begin{array}{l}\text { Psychological adjustment strategies } \\
\text { Social adjustment strategies }\end{array}$ & 1 & & & \\
Physical adjustment strategies & $0.608^{* *}$ & 1 & 1 & \\
Overall test & $0.464^{* *}$ & $0.788^{* *}$ & 1 & 1 \\
\hline
\end{tabular}

Note. ${ }^{*} \alpha$ functional at $(\alpha=0.05),{ }^{* *} \alpha$ functional at $(\alpha=0.01)$.

Table 8

Alpha Internal Consistency and Test Retest Based on the Dimensions and Overall Adjustment Strategies Test

\begin{tabular}{lll}
\hline Dimension & Test Retest & Internal Consistency \\
\hline psychological adjustment strategies & 0.84 & 0.76 \\
social adjustment strategies & 0.87 & 0.71 \\
physical adjustment strategies & 0.88 & 0.71 \\
overall test & 0.86 & 0.87 \\
\hline
\end{tabular}

\section{Procedures}

The study sample was determined from female students $(N=80)$ who were enrolled in the special education department at Qassim university for the academic year 2015/2016, they were distributed equally on two groups according to their studying paths learning difficulties (40 students) and speech disorders ( 40 students).

The test of future attitude toward the profession was implemented before the students start their field training, then after an interval of the five weeks of training (the period of which the students will have an image about the field training) they finished the reality shock test. Followed by implementing the adjustment strategies at the end of the tenth week (the period where the students choose some adjustment strategies to cope with the training situation). Lastly the future attitude toward the profession posttest was implemented at the end of the training period (the end of the thirteenth week).

Variables of the Study: Independent variables. The reality shock among the field training students at the department of special education. Dependent variables. Student's adjustment strategies and future attitude toward the profession.

Design of the study. The study relied on a pre and posttest implementation; the future attitude toward the profession was implemented before students start training, and the reality shock test was implemented on the fifth week of training and the future attitude toward the profession test was implemented again at the end of the tenth week. Table 9 illustrates the design of the study.

Table 9

Design of the Study

\begin{tabular}{|l|l|l|l|l|}
\hline & Posttest After 13 weeks & After 10 weeks & After 5 weeks & Pretest \\
\hline $\begin{array}{l}\text { Future attitude toward } \\
\text { the profession test }\end{array}$ & $\begin{array}{l}\text { Adjustment strategies } \\
\text { test }\end{array}$ & Reality Shock test & $\begin{array}{l}\text { Future attitude toward } \\
\text { the profession test }\end{array}$ & Learning difficulties \\
\hline $\begin{array}{l}\text { Future attitude toward } \\
\text { the profession test }\end{array}$ & $\begin{array}{l}\text { Adjustment strategies } \\
\text { test }\end{array}$ & Reality Shock test & $\begin{array}{l}\text { Future attitude toward } \\
\text { the profession test }\end{array}$ & Speech disorders \\
\hline
\end{tabular}

Statistical analysis. Means, standard deviations $t$-test and Fisher's $Z$ were used in analyzing the data obtained. 


\section{Results and Discussion}

The first question in the study was "What is the field training students exposure degree to reality shock and its dimensions?" Table 10 presents the means and standard deviations based on field training student's exposure to the reality shock and its dimensions.

Table 10

Means and Standard Deviations of Field Training Students Exposure to Reality Shock in Means Descendant Order

\begin{tabular}{lllll}
\hline Item No. & Dimension & Mean & Standard Deviation & Level \\
\hline 1 & Academic supervisor & 3.31 & 0.302 & High \\
2 & Academic and professional preparation & 3.27 & 0.248 & Medium \\
3 & Training student & 3.22 & 0.271 & Medium \\
4 & Cooperative teacher and school administration & 3.17 & 0.311 & Low \\
5 & Students at the special needs school & 3.16 & 0.298 & Low \\
& Overall test & 3.23 & 0.194 & Medium \\
\hline
\end{tabular}

It is inferred from Table 10 that means scored between (3.16-3.31); academic supervisor scored the highest (3.31) followed by academic and professional preparation (3.27) then came the training student (3.22) fourth scored (3.17) by cooperative teacher and school administration and finally the students at the special needs school scored (3.16), the overall mean of reality shock exposure scored (3.23).

From Table 10 results it is inferred that the role of the academic advisor has a critical role which is apparent from adopting and developing programs to help training students to lower the levels of reality shock exposure by providing them with support and help in addition to the exact description of the trainee performance and tasks. But, it seems that the supervisor missed encouraging the training student, providing her with ideas, educational material and new strategies needed in the field of special education and to recognize her own expectations and to increase her awareness of the school system. This may be attributed to the many concerns and engagements of the supervisor, to the large number of training students or lack of qualifications. For this reason the current study recommends of conducting studies that measures the academic supervisor role with the field training students, and the obstacles that might confront her.

The last score of the students at the special needs school of (3.16) signifies that working with this category of students creates feelings of sympathy for the workers, because such a job requires that, each student is considered a special case that requires a special type of service, education, training and support.

The previous result agrees with the results of Muhaisin (1997) that found no effect of reality shock among trainees, and that they were able to deal with all unusual students. But disagree with Kim and Cho (2014) results which showed that reality shock has a negative effect on the efficacy and intrinsic motivation toward the profession.

The second question of "Are there statistical significant differences for the exposure degree to reality shock and its dimensions attributed to the path (learning difficulties and speech disorders)?" results are illustrated in Table 11, by calculating means and standard deviations of the reality shock exposure degree based on their path (learning difficulties and speech disorders), $t$-test is utilized to find the statistical differences between the means. 
Table 11

Means and Standard Deviations and t-test of Students Exposure to Reality Shock Based on Paths

\begin{tabular}{|c|c|c|c|c|c|c|c|}
\hline & Path & $N$ & $M$. & $S D$. & $t$-value & $d f$ & Sig. \\
\hline \multirow{2}{*}{ Training student } & Learning difficulties & 40 & 3.3 & 0.28 & \multirow{2}{*}{0.92} & \multirow{2}{*}{78} & \multirow{2}{*}{0.360} \\
\hline & Speech disorder & 40 & 3.2 & 0.27 & & & \\
\hline \multirow{2}{*}{$\begin{array}{l}\text { Academic and professional } \\
\text { preparation }\end{array}$} & Learning difficulties & 40 & 3.3 & 0.25 & \multirow{2}{*}{0.269} & \multirow{2}{*}{78} & \multirow{2}{*}{0.789} \\
\hline & Speech disorder & 40 & 3.3 & 0.25 & & & \\
\hline \multirow{2}{*}{ Academic supervisor } & Learning difficulties & 40 & 3.2 & 0.3 & \multirow{2}{*}{-3.434} & \multirow{2}{*}{78} & \multirow{2}{*}{0.001} \\
\hline & Speech disorder & 40 & 3.4 & 0.26 & & & \\
\hline \multirow{2}{*}{ Students at the special needs school } & Learning difficulties & 40 & 3.3 & 0.27 & \multirow{2}{*}{4.795} & \multirow{2}{*}{78} & \multirow{2}{*}{0.000} \\
\hline & Speech disorder & 40 & 3.0 & 0.26 & & & \\
\hline \multirow{2}{*}{$\begin{array}{l}\text { Cooperative teacher and school } \\
\text { administration }\end{array}$} & Learning difficulties & 40 & 3.1 & 0.31 & \multirow{2}{*}{-2.167} & \multirow{2}{*}{78} & \multirow{2}{*}{0.033} \\
\hline & Speech disorder & 40 & 3.2 & 0.30 & & & \\
\hline \multirow{2}{*}{ Overall reality shock exposure } & Learning difficulties & 40 & 3.2 & 0.20 & \multirow{2}{*}{0.022} & \multirow{2}{*}{78} & \multirow{2}{*}{0.983} \\
\hline & Speech disorder & 40 & 3.2 & 0.20 & & & \\
\hline
\end{tabular}

From Table 11, it is inferred that there are statistically significant differences at $(\alpha=0.05)$ attributed to the effect of bath with academic supervisor scoring (3.42), with cooperative teacher and school administration scoring (3.24) in favor of speech disorders. Also academic supervisor and cooperative teacher and school administration doesn't seems to have a crucial role in preparing the student for field training which is directly correlated with the educational process that stresses through academic supervisor practices that the students role is traditional summarized by students considered a recipient and a limited participant, where her role is limited by memorizing information in textbooks and store it in the memory then recall it in the exam, which creates a gap between the academic and training reality that causes the reality shock. These results agree with Muhaisin (1997) study which indicated that the main reasons of difficulty of dealing with non-regular patterns of learners is attributed to poor field preparation that is the responsibility of the academic supervisor and the school. The mean of students at the special needs school scored (3.30) in favor of learning difficulties, this is linked with the fact that individuals having learning difficulties need special teaching methods because the regular methods are not suitable for them and those used in teaching retarded are not suitable too. Their development rates differ from one to another that means difficulty in preparing learning processes because of the individual differences which affects the trainee student when starting training. Add to this the poor abilities of some special needs individuals and the diversity of their problems and its intensity may create reality shock among field training students and a sense of accomplishment and success, which may create psychological and professional pressures and thus lead to reality shock. The results in Table 11 agree with Kim and Cho (2014) who proved the negative effect of reality shock on teacher efficacy and intrinsic motivation toward the profession regardless of the path chosen at the university. But Sehba (2013) reveals the reasons of being shocked, the difference between previous perceptions about teaching and its effect on the transfer from being a student to become a teacher, whereas significant differences were not found in other dimensions and overall test.

To answer the third question "Is the relationship between reality shock and students attitude toward the profession attributed to path (learning difficulties and speech disorders) different?", the correlation between reality shock and students attitude toward the profession based on the path (learning difficulties and speech disorder) are calculated, Fisher's $Z$ is calculated to find the strength of the correlation between the two paths as illustrated in Table 12. 
Table 12

Correlations Coefficients Between Reality Shock and Students Attitude Toward the Profession Based on the Path, and Fisher's $Z$ of the Differences Between Coefficients

\begin{tabular}{lllll}
\hline & & $R$ & $N$ & $Z$ \\
\hline \multirow{2}{*}{ Path } & Learning difficulties & $0.315^{*}$ & 40 & \multirow{2}{*}{0.081} \\
& Speech disorders & 0.296 & 40 & \\
\hline
\end{tabular}

Note. ${ }^{*} \alpha$ functional at $(\alpha=0.05)$.

From Table 12, no statistical differences at $(\alpha=0.05)$ in correlation strength is attributed to paths. This result may be explained by the equal academic and professional preparation of both paths. This result disagree with Obani and Doherty (2002), they found that female students teachers had positive attitude toward the profession compared with male students teachers who accepted working with mentally retarded people while female preferred working with blind people. Dignan (2003) found that the reason for choosing to teach special needs students was because they like to work with this category, $13.9 \%$ of them had previous contact with blind people. Haussatter (2007) found that the students at the university chose to be teachers for special needs students because they want to help low achievers to improve and provide them with supervision and guidance while they study. Petrovary (2008) found that the trainees were willing to work with blinds.

To answer the fourth question of "Are there statistical significant differences in pre and posttests of field training students attitudes attributed to toward the profession?", pre and posttest means and standard deviations of field training students attitude toward the profession are calculated, $t$-test is used to find the statistical differences as illustrated in Table 13.

Table 13

Means, Standard Deviations and t-test of Field Training Students Attitude Toward the Profession Pre and Posttests

\begin{tabular}{llllllll}
\hline & Level & $N$ & $M$. & $S D$. & $t$-value & $d f$ & Sig. \\
\hline \multirow{2}{*}{ Attitude toward the profession } & Pretest & 80 & 3.36 & 0.412 & \multirow{2}{*}{-6.735} & \multirow{2}{*}{79} & \multirow{2}{*}{0.000} \\
\cline { 3 - 5 } & Posttest & 80 & 3.14 & 0.268 & & & \\
\hline
\end{tabular}

From Table 13, statistical significant differences at $(\alpha=0.05)$ between pre and posttests in favor of the pretest. This result may be explained by the fact that the transfer from being a student teacher to actual teaching or field training causes him a reality shock according to the study of Weinstein (1988). This shock may lead to the damage of the theoretical ideals because of the harsh facts of the schools of special education as Merrett and Wheldall (1993) asserted. This in turn would result in negative attitudes toward the teaching profession and to the sense of its inappropriateness as Hayon and Beretz (1988) concluded.

To answer the fifth question of "What are the adjustment strategies used by field training students in both paths (learning difficulties and speech disorders) toward reality shock?" means and standard deviations of adjustment strategies for both paths (speech disorders and learning difficulties) toward reality shock are illustrated in Table 14.

In Table 14 it is observed that means scores ranged between (3.45-3.46), psychological and physical adjustment strategies scored first (3.46), this is interpreted by teachers feeling of psychological and academic pressures indicating to stain. Accordingly actions are needed to reduce strains before it transforms chronic disease. In this study, the students resorted to adjustment strategies to reduce their strains. While social 
strategies scored (3.45) and overall test mean scored (3.46). Adjustment strategies varied in the literature review; Bahrawi (2003) found that students having a high level of sociability are characterized by effective and rational with their colleagues more compared with students of low levels of sociability. In Kardum and Karpić's (2003) study, it was found that there is a positive effect of the extroversion personality in confronting problems, and neurological scientists focused on avoidance of confrontation. Raja (2007) study found that students tend to use approach more than avoidant strategies, females tend to use the catharsis strategies.

To answer the sixth question of "Are there statistical significant differences in students adjustment strategies attributed to the path (learning difficulties and speech disorders)?" means and standard deviations of students adjustment strategies based on the paths (speech disorders and learning difficulties) are calculated, and to find the functionality of these differences a $t$-test is implemented as illustrated in Table 15.

Table 14

Means and Standard Deviations of Adjustment Strategies Means Descendant Order

\begin{tabular}{llllll}
\hline Rank & No. & Dimension & $M$. & $S D$. & Level \\
\hline 1 & 1 & Psychological adjustment strategy & 3.46 & 0.267 & High \\
1 & 3 & Physical adjustment strategy & 3.46 & 0.303 & High \\
3 & 2 & Social adjustment strategy & 3.45 & 0.268 & Medium \\
& Overall test & 3.46 & 0.198 & \\
\hline
\end{tabular}

Table 15

Means and Standard Deviations and t-test of Students Adjustment Strategies Based on Paths

\begin{tabular}{llllllll}
\hline Strategy & Path & $N$ & $M$. & $S D$. & $t$-value & $d f$ & Sig. \\
\hline Psychological Adjustment & Learning difficulties & 40 & 3.51 & 0.257 & \multirow{2}{*}{1.67} & 78 & 0.099 \\
Strategy & Speech disorder & 40 & 3.41 & 0.271 & & & \\
Psychological Adjustment & Learning difficulties & 40 & 3.49 & 0.266 & \multirow{2}{*}{1.384} & 78 & 0.17 \\
Strategy & Speech disorder & 40 & 3.41 & 0.267 & & & \multirow{2}{*}{0.379} \\
Physical Adjustment Strategy & Learning difficulties & 40 & 3.49 & 0.301 & \multirow{2}{*}{0.884} & 78 & \multirow{2}{*}{0.07} \\
& Speech disorder & 40 & 3.43 & 0.306 & & & \\
Overall & Learning difficulties & 40 & 3.50 & 0.178 & \multirow{2}{*}{1.836} & 78 & 0.07 \\
\hline
\end{tabular}

It is inferred in Table 15 that no statistical differences are found at $(\alpha=0.05)$ attributed to the path in all the dimensions and overall test. The authors believe that this result may be attributed to the availability of factors expected to help the students to use the same adjustment strategies such as academic preparation, academic supervisor, professional environment similarity and school management all of which motivate students to use the similar adjustment strategies that affect the psychological, physical and social adjustment. The results disagree with Jodah (2004) who found significant differences in confronting stressful life events styles attributed to the path, it also disagree with Raja (2007) who found that students usage of the strategies were majoring in psychological counseling and psychology.

\section{Implications}

The authors are convinced that obstacles that face students professional adjustment of the students of special education and to provide better professional situations and they recommend with.

Equip academic supervisors professionally so they are able to provide the necessary counseling for field training students to help them confront reality shock. 
Design and implement preventive programs to help training students working with special needs students to find better adjustment strategies toward the work difficulties.

Ensure that work load and tasks assigned to the students are appropriate to work with special needs students to prevent their feelings of hopelessness and lack of accomplishment.

\section{References}

Abdel-Azeem, T. (2006). Managing educational and psychological stresses (1st ed.). Amman: Dar El-Fikr.

Alian, M., \& Shakhshir, Kh. (2007). The mechanisms used to award a certificate of practice. A workshop on the complementary relationship between higher education and basic education: The program of training teachers. Palestine: Ministry of Education.

Al-Omary, F. (1989). High school students attitudes in Riyadh toward learning English (Unpublished master's thesis, King Saud University, Riyadh).

Al-Quds Open University. (1997). Intervention in crisis and emergencies: Social and family development program. Amman, Jordan: Al-Quds Open University Press.

Arabyat, A., \& Kharabsheh, O. (2007). Psychological pressures faced by talented students and a strategy to deal with it. Journal of the Federation of Arab Universities and Educational Psychology, 5, 2.

Bahrawi, A. (2003). Psychological and social school stress: Confrontational methods (Unpublished master's thesis, Al-Azhar University, Cairo).

Bootzin, R. R. (1991). Psychology today: An introduction (7th ed.). New York: McGraw-Hill.

Da'na, W. (1994). Supervisors psychological stress in schools of the Ministry of Education Jordan (Unpublished master's thesis abstracts, University of Jordan, Amman).

Dignan, K. (2003). SWOT Analysis of five professions and professional preparation system. AER Executive Report: Preliminary results.

Ganellen, R. J., \& Blaney, P. H. (1984). Hardiness and social support as moderators of the effects of life stress. Journal of Personality and Social Psychology, 47(1), 156-163.

Hallahan, D. P., \& Kauffman, J. M. (1991). Exceptional children: Introduction to special education. Boston: Allyn and Bacon.

Hasan, T. (2006). Psychological and educational stress management. Amman: Dar El-Fikr.

Hausstatter, R. S. (2007). Students' reasons for studying special needs education: Challenges facing inclusive education. Teacher Development, 11(1), 45-57.

Hayon, K. L., \& Peretz, B. M. (1988). Becoming a teacher: The transition from teachers' college to classroom life. International Review of Education, 32(4), 413-422.

Higgins, J. E., \& Endler, N. S. (November 01, 1995). Coping, life stress, and psychological and somatic distress. European Journal of Personality, 9(4), 253-270.

Jodah, A. (2004). Coping styles stressful life events and their relationship to mental health among a sample of students of Al-Aqsa University. Research presented at the First Educational Conference, Islamic University, Palestine.

Kardum, I., \& Krapić, N. (2003). Personality traits, stressfully feevents, and coping styles in early adolescence. Personality and Individual Differences, 30(3), 503-515.

Kim, H., \& Cho, Y. J. (2014). Pre-service teachers' motivation, sense of teaching efficacy, and expectation of reality shock. Asia-pacific Journal of Teacher Education, 42(1), 67-81.

Lazarus, R. S. (1966). Psychological stress and the coping process. New York: McGraw-Hill.

Lazarus, R. S., \& Folkman, S. (1984). Stress, appraisal, and coping. New York: Springer.

Merrett, F., \& Wheldall, K. (1993). How do teachers learn to manage classroom behaviour? A study of teachers' opinions about their initial training with special reference to classroom behavior management. Educational Studies, 19(1), 91-106.

Muhaisin, I. (1997). Practical education students between the university preparation and reality shock. Faculty of Education, University of Qatar, 14, 195-215.

Obani, T., \& Doherty, J. (January 01, 1984). A study of some factors influencing attitudes to teaching the handicapped among Nigerian student teachers. International Journal of Educational Development, 4(4), 285-291.

Petrovay, D. W. (2008). Personality characteristics, career awareness, and job expectations of new teachers of students with visual impairments. Tucson, Arizona: University of Arizona. 


\section{REALITY SHOCK AMONG FIELD TRAINING STUDENTS AT THE SPECIAL EDUCATION 241}

Qaraqzah, S. (2004). Awareness level of graduates of educational faculties in Jordan with educational philosophies and the general philosophy of education in Jordan and its relation to their attitudes towards the profession: a comparison study (Unpublished Ph.D. thesis, Amman Arab University, Jordan).

Raja, M. (2007). Strategies used by students to deal with the psychological pressures. Journal of Arab Universities of Education and Psychology, 5, 146-151.

Sehba, M. (2013). "Reality Shock": Newearly childhood education teachers. Journal of Early Childhood Teacher Education, 34(2), 154-170.

Weinstein, N. D. (1988). The precaution adoption process. Health Psychology, 7(4), 355-386. 